\title{
Government Guidance Fund: a New Innovation Mode of Financing in Marina Bay of Dongguan City
}

\author{
Zengyan Xiao \\ Business School \\ City College of Dongguan University of Technology \\ Dongguan, China
}

\begin{abstract}
The Government guidance fund establishes a number of special sub-funds in the form of a parent fund through cooperation with domestic and foreign financial institutions, enterprises and other social capital. It can solve the financing problems by using leverage. The Marina Bay New District is the new development zone in Dongguan city and is the important part of the Greater Bay Area of Guangdong, Hong Kong and Macau. To some extent, this regional construction can establish government guidance fund to solve the problem of many projects lacking large funding.
\end{abstract}

Keywords-Marina Bay New District; government guidance fund; financing

\section{INTRODUCTION}

The government guidance fund is usually led by the government and aiming at the goal of expanding the fund. It is initiated by a joint financial institution. By investing financial funds, it guides financial and social capital into the investment field. On November 12, 2015, the Ministry of Finance issued the "Interim Measures for Government Investment Funds", which pointed out four major areas supported by the government guidance fund. The four areas are Innovation and entrepreneurship, SMEs, industrial transformation and upgrading, infrastructure and public services.

Marina Bay New District of Dongguan is committed to building a new engine and innovative technology corridor for the development of Dongguan City. So, the Marina Bay focused on developing high-end equipment manufacturing, modern service industry and high-tech industry. From the current construction, the large funding gap is the most difficult problem. Therefore, it is urgent to innovate the financing model to support the construction of the Marina Bay New District. So, the author thinks that establishing the government guidance fund is the best way to resolve the problem.

This article is divided into five parts. Section two introduces the current situation of project construction, investment and financing in the Marina Bay New District. Section three introduces the establishment of government guidance funds in the countries, Guangdong Province and Dongguan City in recent years. Based on this, Section four proposes an innovation mode that is establishing the government guidance fund. The final Section offers the conclusion.

\section{The Status of Project CONSTRUCtion AND FINANCING IN MARINA BAY NEW DISTRICT}

Marina Bay New District locates in Pearl River Estuary, Dongguan City, Guangdong Province, China. It formally established in October 2017. The New District consists of three major sections: Jiaoyi Bay, Shajiao Peninsula and Weiyuan Island, with a planned area of 83 square kilometers. It will draw on the model of the Silicon Valley 101 Highway Innovation Zone in the United States, and strive on creating an international level of Innovation Chain Corridor. In development planning, the New District will not only Comb the traditional advantageous industries, but also will give strong support to the strategic emerging industries by relying on the policy advantages of Guangdong, Hong Kong and Macau. At present, the New District's traditionally advantageous industries include Changan Smart Phone, Humen Clothing Trade, Houjie Furniture Exhibition, Shatin Lingang Industry, etc. In 2017, these indusry's GDP reached about 164.3 billion yuan, accounting for $21.7 \%$ of Dongguan City. The Strategic emerging industries mainly include a new generation of electronic information, artificial intelligence, medical health, technology finance, and high-end equipment manufacturing, etc.

In 2017 , a total of 144.3 billion yuan was invested to the coastal area of New District, accounting for $20 \%$ of Dongguan's GDP. Among them, the overall investment of Guangdong-Hong Kong-Macau Cultural Street is 1 billion yuan, and Shenzhen Ocean Science and Technology R\&D Service Base is 10 billion yuan. On June 21, 2018, the contracted investment amount of Marina Bay New District was about 277 billion yuan. These projects mainly include such as Ziguangxinyun Industrial City, Weiyuan Island's Smart New City, and AI Future Industrial Park.

\section{The Status of GOVERnMENT GUIDANCE FundS}

\section{A. The Overall Development Situation of the National Guidance Fund}

On the one hand, the government guides investment funds play the guiding role of government funds, specifically in attracting social funds to invest to the areas and industries 
which supported by the state. By doing so, it can take full use of the fund in implementing industrial policies, guiding private investment, and stabilizing economic growth.

On the other hand, it also helps to exert the magnifying effect of fiscal funds and improve the efficiency of government funds. In terms of guidance, the government guidance fund can use a variety of methods such as equity participation funds, joint investment and financing guarantees.

In recent years, the establishment of government's investment funds of various provinces in China has experienced a period of rapid development. According to statistics from the Zero2IPO database, as of 2016, China has established more than 800 government guidance funds with a scale of 218 million yuan. Among them, 101 in Zhejiang province, 99 in Shandong province, 89 in Guangdong province, 63 in Jiangsu province , 33 in Shanghai, 59 in Beijing.

\section{B. Establishment of Government Guidance Fund in Guangdong Province}

In recent years, the government's guidance funds have developed rapidly in Guangdong Province, which provided a new impetus for the development of the "new economy" and the conversion of old-new kinetic energy. As can be seen from "Fig. 1", from 2007 to 2016, the number of government guidance Fund's growth in 2015 was the fastest which reached 30, and in 2016which reached 10.

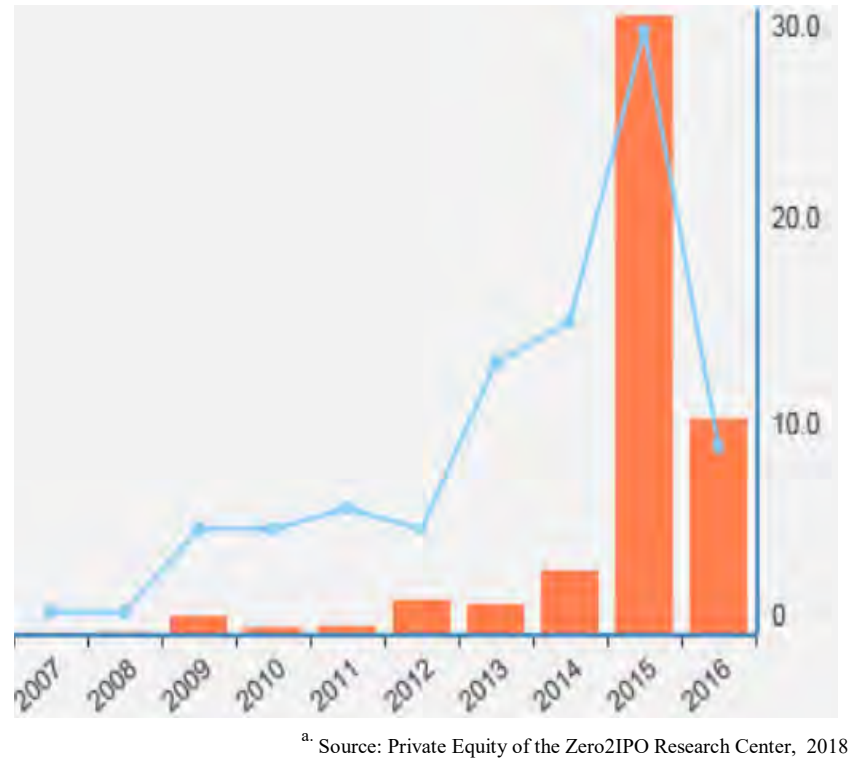

Fig. 1. The number of government guiding Fund's growth.

According to statistics from the Zero2IPO database, in the top 20 Chinese government guidance funds in 2016 , there are 5 in Guangdong Province. They are Shenzhen Guiding Fund (ranked first), Guangdong Yuecai Fund, Shenzhen Futian Guiding Fund, Shenzhen Longgang District Guiding Fund, and Shenzhen Nanshan District Industrial Development Investment Guidance Fund.

\section{Investment Situation of Manufacturing Government Guidance Funds in Dongguan City from 2013 to 2018}

Zero2IPO database show that as of September 27, 2018 , Dongguan has 12 government guidance funds to be invested in manufacturing enterprises. The total fund size exceeds 15 billion yuan, effectively guiding social capital into the manufacturing sector.

TABLE I. INVESTMENT SituATION OF MANUFACTURING GOVERNMENT GUIDANCE FundS IN DONGGUAN CiTY FROM 2013 TO 2018

\begin{tabular}{|l|l|l|}
\hline \multicolumn{1}{|c|}{ Set-up time } & \multicolumn{1}{c|}{ Fund name } & \multicolumn{1}{c|}{ Total size } \\
\hline April 10, 2013 & Dongguan Red Earth Fund & \\
\hline May 26, 2013 & Zhongke Zhongguang Dongguan Equity Investment Fund & 5.5 billion yuan \\
\hline May 10, 2014 & Dongguan Innovation Seed Fund & 0.5 billion yuan \\
\hline January 1,2015 & $\begin{array}{l}\text { Dongguan Science and Technology Achievement } \\
\text { Transformation Guidance Fund }\end{array}$ & 6 billion yuan \\
\hline June 23, 2015 & Changan Industrial Equity Investment Fund & 2 billion yuan \\
\hline October 10, 2015 & Bosch Rui Dexin & 5 billion yuan \\
\hline May 10, 2016 & Changping Shengjing Fund & 1 billion yuan \\
\hline July 13, 2016 & GuangDong guan Shangqing Grand Equity Investment Fund & 8 billion yuan \\
\hline September 30, 2016 & China's third generation semiconductor fund & 20 billion yuan \\
\hline July 11,2017 & Daojiao Emerging Fund & 3 billion yuan \\
\hline June 20,2018 & Dongguan Shijie Haifu Fund & 50 billion yuan \\
\hline
\end{tabular}

Source: Private Equity of the Zero2IPO Research Center, 2018

IV. THE GOVERNMENT GUIDANCE FUND'S INNOVATION ON THE FINANCING MODEL OF MARINA BAY NEW DiSTRICT OF DONGGUAN

The Marina Bay New District of Dongguan is currently in the stage of initial construction, and the industrial layout of the three major sectors is clear: the Weiyuan Island is to create a smart new city, involving these Projects that are marine science and culture centers, international high-level general hospitals, etc. The Shajiao Peninsula plate will build a modern service new city, involving projects such as the Xinwan Yuren Wharf and the Marina Bay Headquarters 
Corridor. The Jiaowan Bay plate will become the core of the intelligent manufacturing industry, involving projects such as Ziguangxin Cloud Industrial City, OPPO and VIVO Intelligent Manufacturing Center, and Urban Digital Economy Center.

At present, the government guidance funds setting in Dongguan directly affects the construction of the Marina Bay and are still rare. Therefore, the introduction of the government guidance fund is an innovative model after PPP and BOT. Especially:

- Firstly, the government guidance funds can give full play to the leverage effect of fiscal funds and guide social capital into the field of venture capital. By doing so, it can create a virtuous circle and guide the investment of follow-up funds. Such as guiding the funds to the construction of the Forest Park and the Wisdom New Town in the Wei Island Plate.

- Secondly, the government guidance funds can be conducive to breaking the bottleneck of financing in the real economy and promoting the docking of industry and capital. Dongguan is at the forefront of reform and opening up, so the private capital is relatively strong. Based on this, the government guidance funds can direct and pool these capitals to the modern service new city, Fisherman's Wharf and other projects in the Shajiao Peninsula.

- Thirdly, the government guidance funds can innovate the industrial financing chain and improve the accuracy of industrial support. At present, the Jiaoyiwan Bay Plate is trying to build an intelligent manufacturing center, thus many high-tech enterprises are in urgent need of industrial support funds in the growth period. Based on this, government guidance funds can well absorb venture capital funds and support high-tech enterprises to innovate and start businesses.

\section{CONCLUSION}

This paper starts with the current situation of the construction of Binhai New Area Project in Dongguan, and analyzes the huge gap in current investment and financing.

- Combining the establishment of government guidance funds at the national, provincial and municipal levels, it demonstrates that the government guidance fund supports the construction of the Marina Bay New District in Dongguan, which is a new financing innovation model.

- It is possible for the Dongguan Municipal People's Government to initiate the establishment of a government guidance fund to introduce social capital. By doing so, it can solve the problem of difficult projects in the construction of the Marina Bay New District in Dongguan through leverage.

- The establishment of the government guidance fund is an innovation of the financing model of the Marina Bay New District in Dongguan. It can well support the development of strategic emerging industries, advanced manufacturing and high-end service industries in the Marina Bay New District.

\section{REFERENCES}

[1] Zhang Yiwen. The problems and countermeasures of China's venture capital guiding funds. Economic Aspect. vol.7.2014, pp. 87-90.

[2] Tu Chenglin, Chen Wendong. Dongguan Economic Development Report (2017), Social Sciences Academic Press. 2017, pp. 181-182.

[3] Lin Saiyan, Xie Hong. The institutional problems and development paths of government-led investment funds in the context of marketing. Zhejiang Province Finance, vol.10. 2014, pp. 21-24.

[4] China Investment Development Report. Social Sciences Academic Press, 2017, pp. 166-176.

[5] Yang Minli, Wang Wei, Dong Jianwei. Government guidance funds can guide social funds into the venture capital market. China Science and Technology Forum. vol.11. 2015, pp. 107-111. 